Send your letters to the Editor,

British Dental Journal,

64 Wimpole Street

London

W1G 8YS

Email bdj@bda.org

Priority will be given to letters less than 500 words long.

Authors must sign the letter, which

may be edited for reasons of space.

\section{GREATLY WORRIED}

Sir, your letter from J. Mew Occlusal conflict (BDJ 2009; 206: 56) worried me greatly.

The natural mandibular rest position in the majority of cases has the teeth apart, but lips together. Where there is either a short upper lip or significant skeletal base discrepancy, then the natural rest position may have the lips apart, but the teeth remain apart also.

Electro-myographic studies undertaken by Greenwood in the 1960s and Juniper in the 1970s confirms this. A fact that is generally understood and accepted, though not by Mr Mew. I note that he writes to you quite frequently and, until now, I have not been in a position to determine whether his thoughts are helpful or destructive.

The product of a tooth contact rest position is muscle fatigue, such interrupts normal proprioceptive feedback to the motor cortex. Nature's response is then to produce tooth contact in order that proprioceptive feedback is established through the teeth. However, this maintains the mechanical overload and is one of the primary causes of temporomandibular joint pain dysfunction. I cannot therefore let Mr Mew's comments pass, unaddressed, for if my colleagues follow his advice, then the incidence of temporomandibular joint pain dysfunction will inevitably increase significantly.

Surely our profession should be aiming to prevent, rather than treat, or even encourage, such a problem.

B. Littler Chelmsford

DOI: 10.1038/sj.bdj.2009.216

\section{SADDENED}

Sir, having recently retired I now use my exacting dental skills opening envelopes for the organiser of the Benevolent Fund Christmas Draw. I also collect envelopes from the Post Office from those who have 'forgotten' to place a stamp on the envelope. I am impressed by the generosity of the individuals in our profession who help others who are needy, and I expect these problems will increase in the current climate. I expect most dentists give to charities in various ways and I would always respect the choice of a person to support a particular cause.

However, I was saddened this year by the caring health professional who took the trouble to send in a million pound note from the Bank of Make Believe (aren't they all!) Needless to say there was no name, and no stamp on the envelope. Perhaps the person involved was amused, but there are many who have been helped by the Ben Fund who are not, and I am just getting a grumpy old pensioner.

The Ben Fund will also feel the crunch of the present financial crisis and put more pressure on those who help our colleagues. Except perhaps for the one individual who I hope never finds they are in need.

\section{J. Phipps \\ Sevenoaks}

DOI: 10.1038/sj.bdj.2009.217

\section{DOT, DOT, DASH, DASH}

Sir, I am currently working in my first year of general dental practice and enjoy hearing stories of patients' previous dental experiences.

A 68-year-old gentleman told me that he worked as a navigator in the merchant navy between 1970 and 1977. In 1973 whilst out at sea he started to feel vibrations in his mouth which interrupted his sleep. He later realised that he was picking up the Morse code signals received by the ship through his amalgam fillings. This was confirmed when he correctly interpreted a Morse code message to a colleague via the vibrations!

The problem settled when he left the navy but later recurred when he lived close to Yeadon Airport in Leeds. A local dentist offered to replace his 18 fillings but he declined and the problem settled once again when he moved area.

As a child the patient lived in different places in England and Scotland and thinks the fillings were all different mixes of metals.

Have any other readers come across this phenomenon before?

E. Hutchinson Leeds

DOI: 10.1038/sj.bdj.2009.218

\section{VARYING OPINIONS}

Sir, we were interested to read the letter entitled Sedation in Europe ${ }^{1}$ commenting on our paper concerned with the use of intranasal and intravenous sedation for the treatment of adults with learning disability. ${ }^{2}$ This letter also refers to a paper by McKenna and Manton on fasting for intravenous conscious sedation. ${ }^{3}$ Whilst we do not wish to respond to their comments on this publication we would agree that the provision of conscious sedation does not routinely require a starving regimen advised for the provision of general anaesthesia. However, varying opinions may still be held on this matter and the paper by McKenna and Manton based on an examination of the literature is helpful in airing this issue.

With regard to the use of intranasal midazolam, Zanette, Facco and Manini refer to two aspects of its use. For the 
sedation of children as referred to in a paper by Gilchrist et $a l^{4}$ this may be regarded as an advanced technique and therefore subject to the guidelines set out in the report by the Standing Dental Advisory Committee. ${ }^{5}$ However, these guidelines clearly state that the use of intranasal followed by intravenous midazolam conscious sedation for adults is a standard technique and evidence from our paper supports its safety and efficacy. The comments in this part of their letter (ie 'or adult patients') are therefore incorrect and misleading. The guidelines quoted state on page 11 that 'the pharmacokinetic characteristics of midazolam make it the preferred choice' [for oral and transmucosal sedation] and it is our experience that the preparation concentrated at $40 \mathrm{mg} / \mathrm{ml}$ is particularly useful for both intranasal and oral use.

The GDC clearly state that dentists have a duty and responsibility to make provision for the management of pain and anxiety in their patients and the use of basic conscious sedation has been shown to be safe and effective. In addition, the use of operator sedationist techniques by the general dental practitioner within primary care enables a wide availability of such techniques. Their performance almost solely by anaesthesiologists, as in Italy, may lead to a limitation of the availability of conscious sedation in primary care and perpetuate the well documented inequalities in oral health for adults with severe disability. The Dental Sedation Teachers Group (DSTG 2008) have recently published a proposal for a standard core postgraduate sedation programme for UK dentists. Perhaps this approach could be adopted by European schools so that the same benefits are available to these patients across Europe?

M. C. G. Manley, N. J. Ransford, D. A. Lewis, S. A. Thompson, M. Forbes

P.S. There was a slight confusion in the referencing system of their letter, however, this did not distract from the overall thrust of their comment!

1. Zanette G, Facco E, Manini G. Sedation in Europe. Br Dent J 2008; 205: 523.

2. Manley M C G, Ransford N J, Lewis D A, Thompson $S$ A, Forbes M. Retrospective audit of the efficacy and safety of the combined intranasal/intravenous midazolam sedation technique for the dental treatment of adults with learning disability. $\mathrm{Br}$
Dent J 2008; 205: E3.

3. McKenna G, Manton S. Pre-operative fasting for intravenous conscious sedation used in dental treatment: are conclusions based on relative risk management or evidence? Br Dent J 2008; 205: 173-176.

4. Gilchrist F, Cairn A M, Leich J A. The use of intranasal midazolam in the treatment of paediatric dental patients. Anaesthesia 2007; 62: 1262-1265.

5. Standards for Conscious Sedation in Dentistry: Alternative Techniques. A report from The Standing Committee on Sedation for Dentistry 2007.

DOI: 10.1038/sj.bdj.2009.219

\section{RECREATIONAL QAT}

Sir, we enjoyed reading the recent paper concerning qat and its health effects (BDJ 2009; 260: 17-21). We have come across several patients originating from Somalia and Yemen, who are habitual qat users, purchasing the qat locally in Manchester. As the authors indicate, there is a lack of good quality evidence as to the long-term effects on oral health. The rise in qat use in the United Kingdom has been facilitated by the improvement of air transportation. The most active psychotropic constituent, cathinone, quickly breaks down within days to weaker psychoactive ingredients. Hence, the quicker the qat is chewed after picking, the more potent its effects.

At present, qat is predominantly used in the UK by immigrants from Southern Arabia and Eastern Africa. There is, however, some evidence of its wider use in the community. An investigation of recreational drug use in 'raves' in the Edinburgh area found the use of qat based products to be the second most popular drug taken after ecstasy. ${ }^{1}$ Whether the use of qat will become more widespread with time remains unclear.

B. P. Rajlawat

M. N. Pemberton

- Brown E R S, Jarvie D R, Simpson D. Use of drugs at 'raves'. Scott Med J 1995; 40: 168-171.

\section{DOI: $10.1038 /$ sj.bdj.2009.220}

\section{OBLIQUE RADIOGRAPHS}

Sir, I wonder if any of your members can help. As a dental student I was fortunate enough to be taught by Rita Mason and Professor G. Seward of The London Hospital. The technique of taking oblique lateral radiographs was well taught and often used for clarification of fine detail, where rotational tomograms had too much distortion or loss of information due to the focal trough or where the patient was unable to tolerate the periapical of lower third molars.

Having been a Senior Dental Officer in Special Care Dentistry since 1994 I have used this technique routinely where patients have been unable to tolerate/cooperate sufficiently for intra oral radiographs or a rotational tomogram. Or where the anatomy or physical posture of the patient also preludes the taking of the 'OPT' ie the patient with severe arthritis of the neck and TMJ with the neck fixed flexion and limited jaw opening. The patient with Parkinson/MS/Huntingdon's/Chorea etc who is unable to remain still due to involuntary spasms with tremors. The patient with Down's syndrome where neck and shoulders anatomy may cause difficulty. Or the patient under general anaesthesia who has been unable to cooperate prior to GA for radiographs. With oblique lateral radiographs the head is supported with vacuum pillows/sandbags and takes 0.20 seconds to take rather than the much lengthier OPT and consequently less exposure to radiation.

Latterly we have been unable to obtain films/cassettes/intensifying screens. The general comment is everything is now digital and these old fashioned techniques are no longer of use. These new wonderful techniques of CDCT and digital OPTs are super if you have full patient cooperation or an 'average' anatomy. If not, we are unable to use fully the diagnostic tools available to 'mainstream' patients and this can compromise our diagnosis and treatment planning for patients. Having worked in a unit where X-rays were not available under GA, and then became available, especially oblique laterals/bimolars I noticed significant difference in diagnosis and therefore treatment outcomes.

If any members know where we can obtain these I would be most grateful for the information. If no longer available how does that leave the most vulnerable members of our society regarding equality of outcome of care?

G. A. Greenwood Bridlington DOI: 10.1038/sj.bdj.2009.221 